\title{
Fibrous Dysplasia in the Epiphysis of the Distal Femur
}

\author{
Jung Ho Noh, $\mathrm{MD}, \mathrm{PhD}^{1}$ and Jae Woo Lee, $\mathrm{MD}^{2}$
}

${ }^{1}$ Department of Orthopaedic Surgery, Kangwon National University School of Medicine, Chuncheon; ${ }^{2}$ Department of Orthopaedic Surgery, Kangwon National University Hospital, Chuncheon, Korea

Fibrous dysplasia is a common benign skeletal lesion that may involve a single bone or multiple bones. Although fibrous dysplasia can affect any bone, monostotic fibrous dysplasia of the long bone typically occurs in the diaphysis or metaphysis. We report a very rare case of monostotic fibrous dysplasia involving the epiphysis of the distal femur in a young man.

Keywords: Femur, Epiphysis, Fibrous dysplasia

Fibrous dysplasia is a chronic condition of the bone in which abnormal tissue develops in place of a normal bone. Although any bone may be affected, fibrous dysplasia is commonly found in the diaphyses or metaphyses of long bones. Few cases of monostotic fibrous dysplasia involving the epiphysis have been reported. There have been no reports of the distal femoral epiphysis to the best of our knowledge. Here, we present a rare case of monostotic fibrous dysplasia arising in the epiphysis of the distal femur in a young man. Written informed consent was obtained from the patient to publish this case report, including the images.

\section{Case Report}

A 17-year-old man visited our hospital because of an abnormal finding on a simple radiograph of the right knee that was taken in a primary care clinic for constitutional varus knee. The subject

Received February 20, 2016; Revised (1st) April 1, 2016;

(2nd) April 13, 2016; Accepted April 22, 2016

Correspondence to: Jung Ho Noh, MD, PhD

Department of Orthopaedic Surgery, Kangwon National University School of Medicine, 1 Gangwondaehak-gil, Chuncheon 24341, Korea Tel: +82-33-258-9213, Fax: +82-33-258-2149

E-mail: bestknee@hotmail.com

Source of funding: This study was supported by 2015 Research Grant from Kangwon National University (no. 520150336).

This is an Open Access article distributed under the terms of the Creative Commons Attribution Non-Commercial License (http://creativecommons.org/licenses/by-nc/4.0/) which permits unrestricted non-commercial use, distribution, and reproduction in any medium, provided the original work is properly cited. reported no pain. Physical examination revealed no tenderness, swelling, effusion, or limitation of motion of the knee. He did not have any history of trauma or medical illnesses.

Plain radiographs of the right knee demonstrated a $25 \times 25 \times 20$ $\mathrm{mm}$ well-defined multi-septated osteolytic lesion in the epiphysis of the distal femur with sclerotic rim. There was no significant change in the contour of the cortex (Fig. 1). Gadoliniumenhanced magnetic resonance imaging (MRI) was performed (Fig. 2). The MRI showed an eccentric lobulated contoured mass in the lateral femoral condyle, which displayed heterogeneous intermediate signal intensity on a T1-weighted image and heterogeneous high signal intensity on a T2-weighted image. The lesion showed strong gadolinium enhancement. There was no metaphyseal or soft tissue encroachment. Neither was there significant bone marrow or soft tissue edema. Based on the radiologic findings, chondroblastoma, giant cell tumor, chondromyxoid fibroma, and fibrous dysplasia were considered as differential diagnoses.

Curettage and autogenous bone graft were performed through a cortical fenestration to prevent collapse of the articular surface. The mass was grossly gritty-feeling, firm, solid, and white. Histologic findings showed curvilinear trabeculae of metaplastic woven bone in a hypocellular, fibroblastic stroma (Fig. 3). Osteoblastic rimming was conspicuously absent. The fibroblastic stroma showed low cellularity and consisted of myxoid material in a collagenous matrix. Collections of foam cells with macrophages were also present. A few multinucleate giant cells were present. Fibroblastic proliferation and some foamy macrophages 

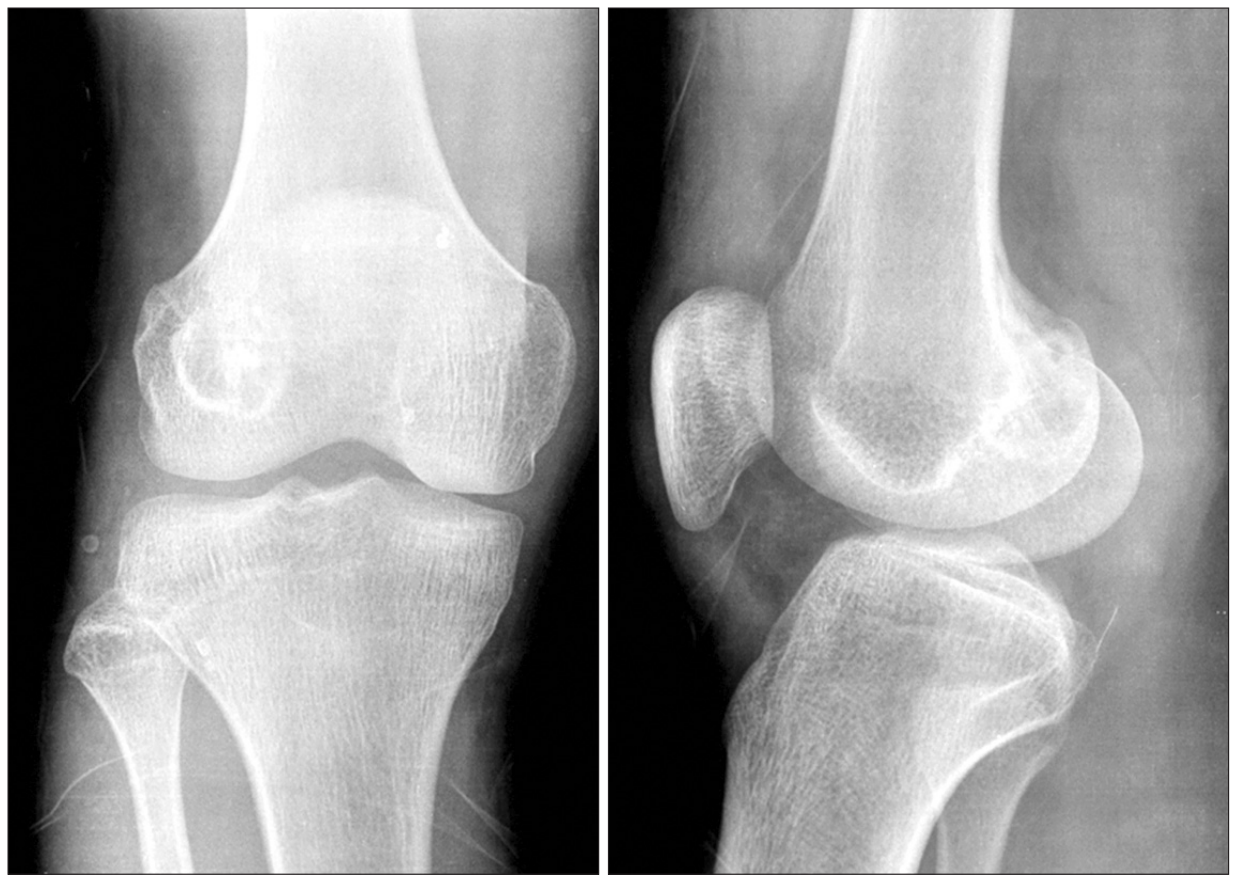

Fig. 1. Plain radiographs of the right knee show a radiolucent lesion with sclerotic contours in the epiphysis of the distal femur.

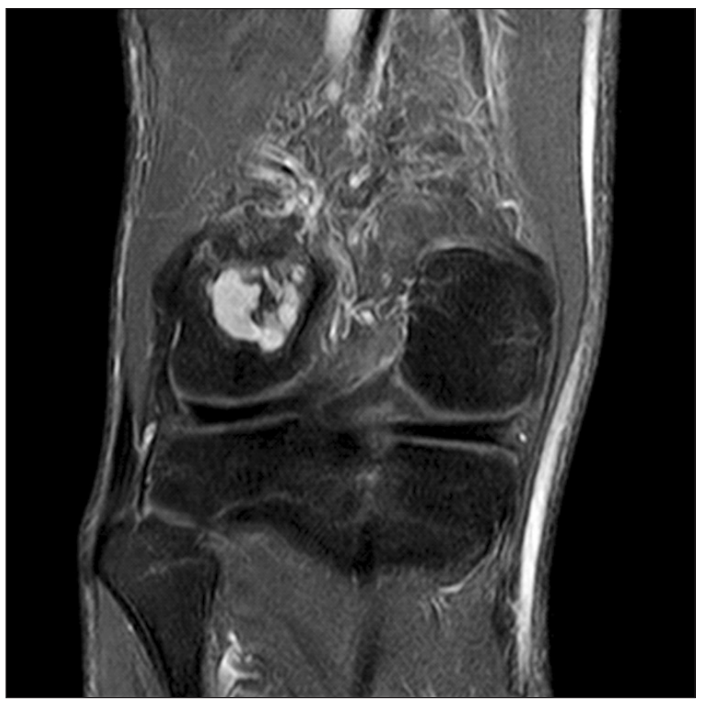

Fig. 2. Gadolinium-enhanced T1-weighted magnetic resonance imaging shows an eccentric, lobulated mass with heterogeneous high signal intensity in the epiphysis of the lateral femoral condyle.

with disorganized bony trabeculae were histological features corresponding to fibrous dysplasia. The lesion did not recur during the 3-year follow-up period.

\section{Discussion}

Fibrous dysplasia accounts for $5 \%-7 \%$ of all benign bone tumors $^{1)}$ and may involve one bone (monostotic) or multiple bones (polyostotic). Although any bone may be affected, fibrous dysplasia is typically found in the diaphyses or the metaphyses in cases affecting long bones. Some authors have reported cases of polyostotic fibrous dysplasia involving the epiphyses ${ }^{2,3}$. However, epiphyseal involvement in monostotic fibrous dysplasia is extremely rare. To our knowledge, involvement of the distal femoral epiphysis, as in our subject, has not been previously reported. Monostotic fibrous dysplasia usually manifests between 20 and 30 years of age and most commonly affects the femurs or the ribs ${ }^{4,5}$. Monostotic lesions are generally asymptomatic and incidentally discovered ${ }^{15}$. However, they often enlarge in proportion to skeletal growth ${ }^{6}$. Diagnosis is usually based on clinical, radiographic, and histopathologic features ${ }^{7}$. On simple radiographs, fibrous dysplasia presents as a well-marginated peripheral sclerotic bone lesion; it shows a variety of patterns, which may be lucent, sclerotic, or mixed, or may have the appearance of ground glass, depending on the amount of bone trabeculae and fibrous elements. Differential diagnoses for such lesions should include epiphyseal lesions such as chondroblastoma, chondomyxoid fibroma, or giant cell tumor. Chondroblastoma is usually seen as a well-defined radiolucent lesion, with a margin that is either smooth or lobulated, and a thin sclerotic rim. However, intralesional calcification can be seen in up to $40 \%-60 \%$ of cases $^{8,99}$. Chondromyxoid fibroma is often seen as a lobulated, eccentric radiolucent lesion, mostly with a well-defined sclerotic margin. Septation is seen in about $50 \%$ of cases and matrix calcification may also be present ${ }^{10)}$. Giant cell tumor is usually lytic, eccen- 

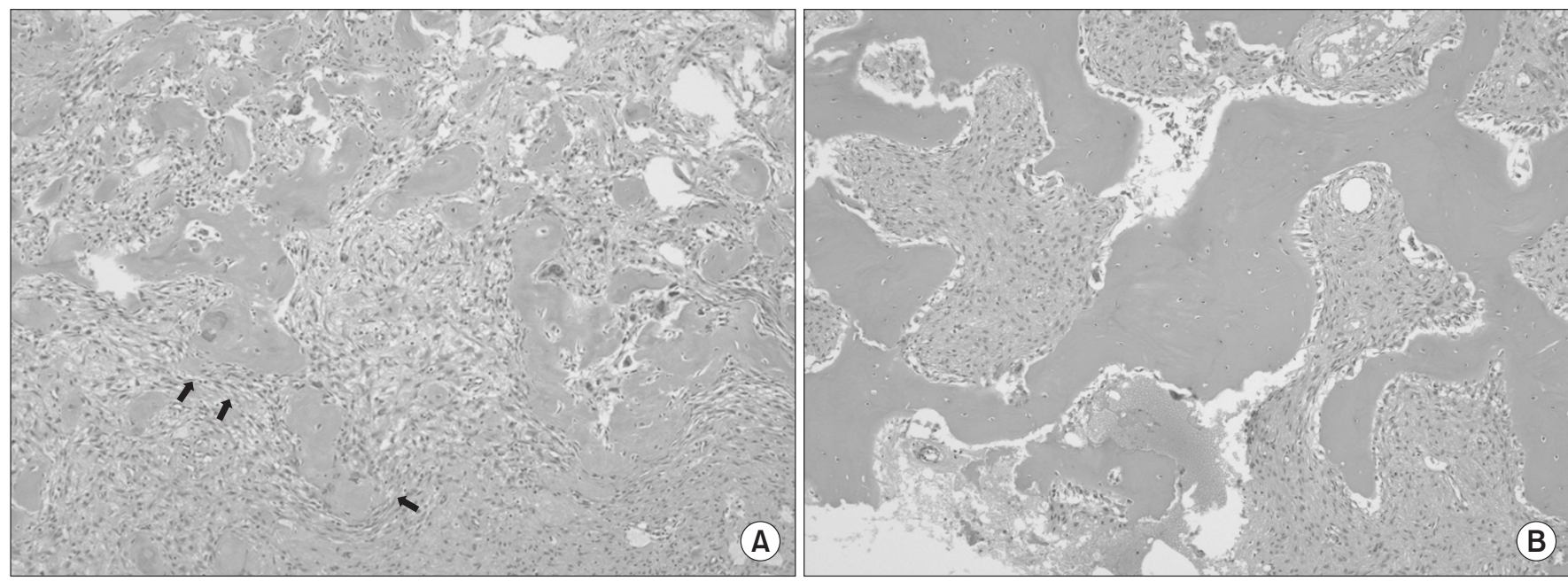

Fig. 3. (A) Microscopic findings of the excised lesion demonstrate spindle cells in a storiform pattern (arrows) around haphazard bony trabeculae and fibrous tissue stroma $(\mathrm{H} \& \mathrm{E}, \times 40)$. (B) There is lack of osteoblast rimming surrounding the trabeculae $(\mathrm{H} \& \mathrm{E}, \times 400)$.

tric, and often lacks a sclerotic rim. However, unusual variants may render radiographic diagnosis difficult, definite a diagnosis should be based on pathologic findings, especially in cases such as this one.

Although most cases of fibrous dysplasia are asymptomatic and do not progress with age, and thus do not require surgical treatment, juxta-articular lesions in weight-bearing joints, as in our case, may need a surgical treatment to prevent articular surface collapse leading to deterioration of joint function.

\section{Conflict of Interest}

This study is supported by 2015 Research Grant from Kangwon National University (No. 520150336).

\section{References}

1. DiCaprio MR, Enneking WF. Fibrous dysplasia: pathophysiology, evaluation, and treatment. J Bone Joint Surg Am. 2005;87:1848-64.

2. Nixon GW, Condon VR. Epiphyseal involvement in polyostotic fibrous dysplasia: a report of two cases. Radiology. 1973;106:167-70.

3. Fukui T, Kawamoto T, Hitora T, Yamagami Y, Akisue T, Yamamoto T. Polyostotic fibrous dysplasia with epiphyseal involvement in long bones: a case report. Case Rep Orthop. 2013;2013:715402.

4. Favus MJ, Vokes TJ. Paget disease and other dysplasias of bone. In: Fauci AS, Braunwald E, Kasper DL, Hauser SL, Longo DL, Jameson JL, Loscalzo J, eds. Harrison's principles of internal medicine. 17th ed. New York: McGraw-Hill Professional; 2008. p2408-16.

5. Ricalde P, Horswell BB. Craniofacial fibrous dysplasia of the fronto-orbital region: a case series and literature review. J Oral Maxillofac Surg. 2001;59:157-67.

6. Henry A. Monostotic fibrous dysplasia. J Bone Joint Surg Br. 1969;51:300-6.

7. Collins MT, Riminucci M, Bianco P. Fibrous dysplasia. In: Rosen CJ, Compston JE, Lian JB, eds. Primer on the metabolic bone diseases and disorders of mineral metabolism. 7th ed. Hoboken, NJ: John Wiley \& Sons; 2008. p423-27.

8. Brower AC, Moser RP, Kransdorf MJ. The frequency and diagnostic significance of periostitis in chondroblastoma. AJR Am J Roentgenol. 1990;154:309-14.

9. Kricun ME, Kricun R, Haskin ME. Chondroblastoma of the calcaneus: radiographic features with emphasis on location. AJR Am J Roentgenol. 1977;128:613-6.

10. Wilson AJ, Kyriakos M, Ackerman LV. Chondromyxoid fibroma: radiographic appearance in 38 cases and in a review of the literature. Radiology. 1991;179:513-8. 